\title{
Measurement and Denoising of Partial Discharge Signal in High Voltage Cables using Wavelet Transform
}

\author{
S. Madhupriya, R. V. Maheswari, B. Vigneshwaran
}

\begin{abstract}
A huge amount of exploration propagated over the past decade investigates the characterization of Partial Discharge (PD) inception in cable ideology. Underground cables are passed down as surrogate for over hauling in congested areas. The intention of this research is to examine the feasibility of exploring insulation defects present in High Voltage $(\mathrm{HV})$ Cable setup by employing $P D$ disclosure under alternating current $(A C)$ Voltage. Study of PD characteristics has a congregate of predictable distinguished contraption to prove the probity and the affirmation of electrical insulation of Power System. In this work, the cable is exposed into the measurement of PD signal under artificially conceived defects. PD signal parameters are mainly depends on the size of void and applied voltage. In general, the measured PD signal is depraved with interferences. To identify the exact characteristics of $P D$ distinctive and its severity, the PD signal is subjected to Wavelet Transform (WT) for denoising. Different types of WT families with various level is used for de-noising. To identify the effectiveness of the WT for de-noising guidelines like Signal to Reconstruction Error Ratio (SRER) and Reduction in Noise Level (RNL) are used.
\end{abstract}

Keywords: Partial discharge, Wavelet transform, Signal to Reconstruction Error Ratio (SRER) and Reduction in Noise Level (RNL)

\section{INTRODUCTION}

Partial discharge (PD) assessment is an crucial symptomatic contrivance for insulation systems as retrieve culminate can be worn to compute the accustom of high voltage farm. PD unremarkably materialized at defeatists like voids, dent, breach, juncture and delamination [1]. These will manifest in solids, liquids and aerosolized dielectrics. The injury because of the discharge may be calculable looking on the kind of discharges; for instance, internal or surface discharge, termination discharge, corona, electrical treeing, etc., [3]. Cables are extensively pre-owned in potential dispersion and transmittal channel in debt its excellent electrical, mechanical and thermal features. Deficiency might be imported in the operation of carry or established, although cable accomplishing is upgraded. In an empirical working situation, electric field laceration throughout these defects is reshape, exceeding unfavorable possessions upon the XLPE insulation disintegration [2].

Revised Manuscript Received on December 30, 2019.

* Correspondence Author

S. Madhupriya,* Department of EEE, National Engineering College, Kovilpatti (Tamil Nadu) India.

Dr. R. V. Maheswari, Professor, Department of EEE, National Engineering College, Kovilpatti (Tamil Nadu) India.

Mr. B. Vigneshwaran, Assistant Professor, Department of EEE, National Engineering College, Kovilpatti (Tamil Nadu) India.

(C) The Authors. Published by Blue Eyes Intelligence Engineering and Sciences Publication (BEIESP). This is an open access article under the CC BY-NC-ND license (http://creativecommons.org/licenses/by-nc-nd/4.0/)

Therefore, as PD audit has incline a cardinal device in estimate the attainment of insulation materials, the designing of PD is valuable in supposing a excelling recognition of PD development [5]. So the artificial defects such as cylindrical void is created in cables will provide a better perception of PD characteristics and also prevent a cables from failure [4]. The connotation of PD on the vigor of insulation has been diagnosed. In PD estimation, eruption can appearing virtue of various species of origin and can span with the structure in contrastive techniques and with contrastive visage. In view of the peradventure to miniature domain of $\mathrm{PD}$ beacon it is veridicality to demise them. Therefore, it's necessary to denoise by many techniques. Because of the prevalence of various interferences within the Partial discharge signal, it's necessary to extract those original signals from creaky signal. Within the previous couple of years, many techniques were spring with denoise the PD signals cogently. However it can be complete either the time domain or within the frequency domain. Once the signal method is completed at intervals the frequency domain, the time domain information is lost. Newer the Wavelet Transform (WT) is sanctioned as a powerful tool for PD process as a result of it preserves each time and frequency domains data.

\section{SAMPLE, EXPERIMENTAL SETUP AND PROCEDURE}

\section{A. Cylindrical Void}

Cylindrical Void with $2 \mathrm{~mm}$ and $5 \mathrm{~mm}$ depth and constant diameter $4 \mathrm{~mm}$ is created in low tension cable by using drilling machine. The depth of the void is measured by using vernier caliper.

\section{B. Experimental Setup}

Partial Discharge measure by using coupling capacitor, testing transformer. The power supply is given as per Fig 1. Fig 1 shows the PD testing connection having merging capacitance, high voltage test transformer, and establish to detain a XLPE cable. The transformer ranked voltage is $2 \times 0.22 / 100 / 0.22 \mathrm{kV}$, ranked current $2 \times 22.8 / 0.1 \mathrm{~A}$, ranked output is $10 \mathrm{kVA}$. Measuring transformer is worn to composed Alternating Current, Direct Current, and impulse voltage. Electric source is given to cable bits by means of transformer. Fig 2 shows a control desk is worn to curb and perform high voltage AC test furnishings. Test arrangement is composed by means of control desk. The PD audit can be eminent from the curb desk, PD meter and computer. 


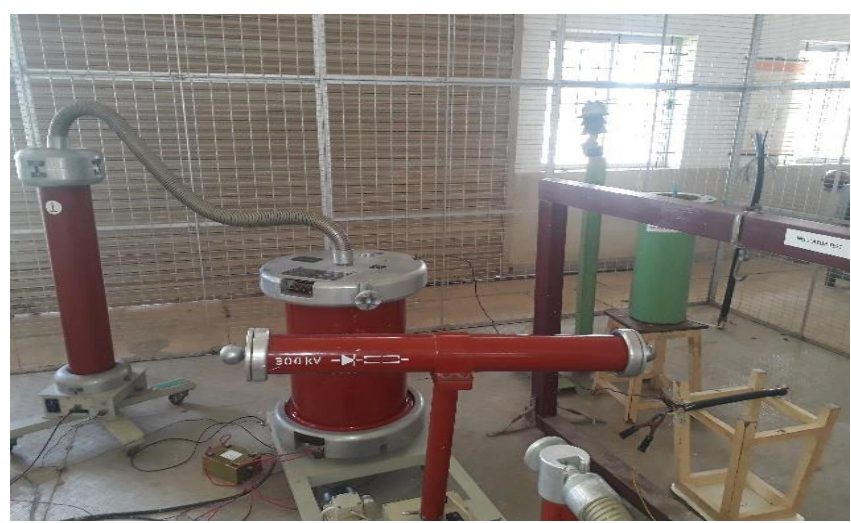

Fig.1. Experimental setup

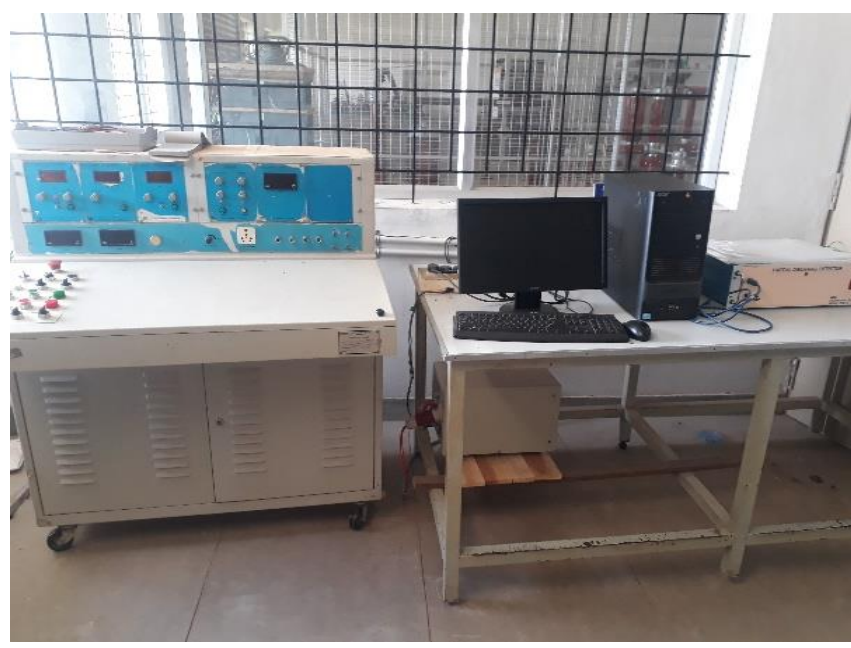

Fig.2. Control panel

\section{Samples}

The investigated cable mainly consisted of a stranded aluminium conductor, an insulation of XLPE, an inner sheath layer and armouring and cable outer sheath. XLPE cable samples have length 1 feet. Before test the cable sheath and insulation were carefully peeled. Fig. 3, 4 and 5 shows a test samples of cables.

Low Tension Cable: $1.1 \mathrm{kV}$

Cross sectional Area: 35 square mm

Insulation thickness: $0.9 \mathrm{~mm}$ (XLPE) [R-Y-B-N]

Number of conductor: 6 (Aluminium)

Minimum outer sheath Thickness: $1.4 \mathrm{~mm}$ (PVC)

Minimum inner sheath Thickness: $0.3 \mathrm{~mm}$ (PVC)

Armouring: Galvanized steel, flat strip

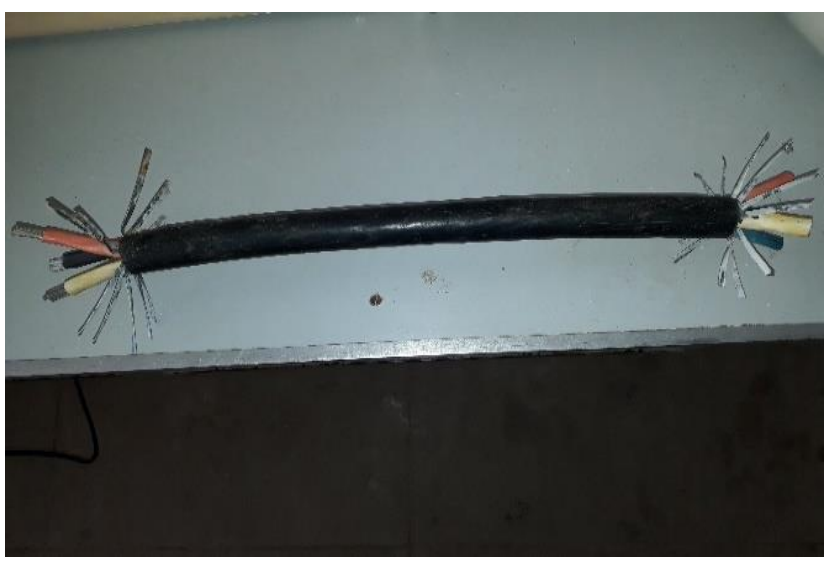

Fig.3. Pure cable

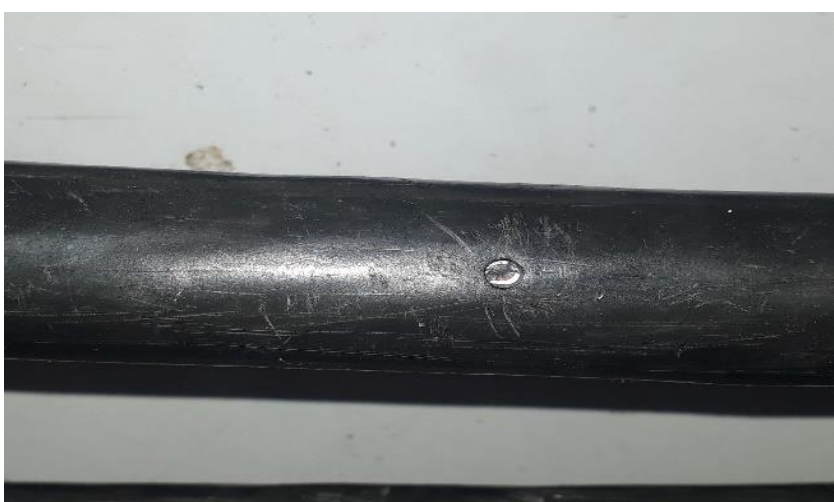

Fig.4. Cylindrical void with $2 \mathrm{~mm}$ depth

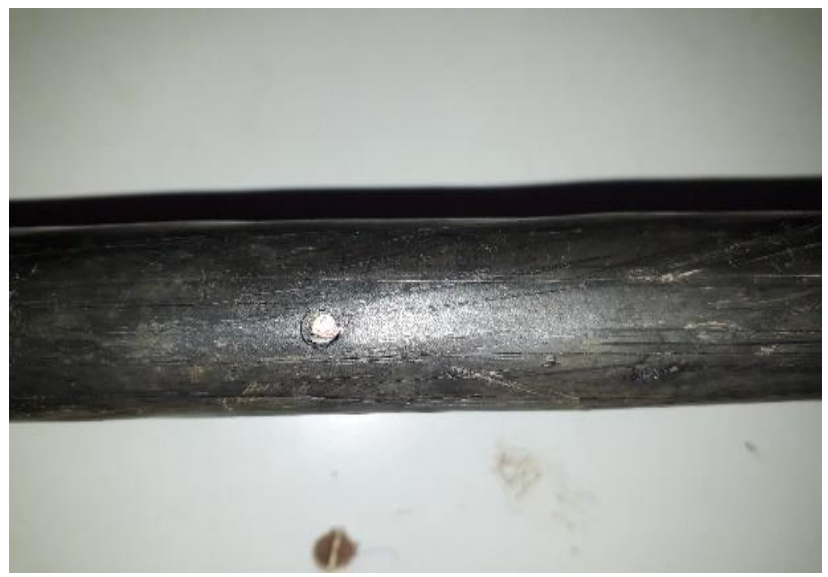

Fig.5. Cylindrical void with $5 \mathrm{~mm}$ depth

\section{Procedure}

The transformer output terminal is connected to the Cable. Before that $2 \mathrm{~mm}$ and $5 \mathrm{~mm}$ void is created on the cable. Voltage is applied on the cable. PD waveform is captured by partial discharge meter. Fig. 6 shows a Schematic diagram of the test object.

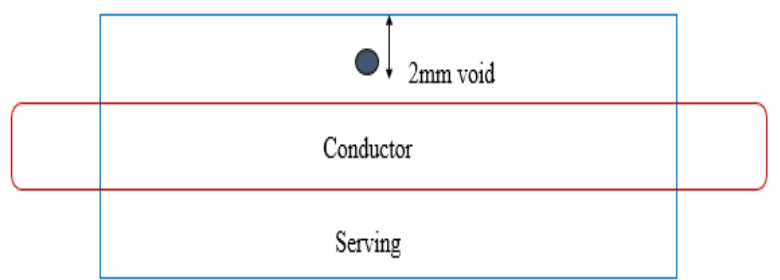

Fig. 6. Schematic diagram of the test object

\section{PARTIAL DISCHARGE}

In engineering, partial discharge (PD) could be a localized dielectric failure (which doesn't fully form the bridge the distance between the 2 conductors) of limited low portion of a solid or fluid electrical insulation scheme under high voltage (HV) emphasis[6].In paperinsulated high-voltage power phases, partial discharges establish as trifle pricks ingoing the paper windings that are beside to the electrical conductor or outer sheath [7].

Published By:

Blue Eyes Intelligence Engineering \& Sciences Publication

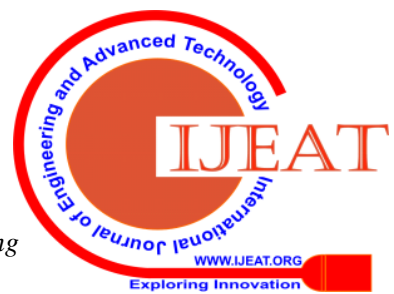


As Partial discharge bustleimprovement, the monotonouspardon eventually create durable chemical variance at parenthesis the troubled paper tiers and infuse dielectric fluent [8]. Additional time, partly escort carbonized branches are forged. This places preeminent emphasis on the tarrying insulation, emerging in additional progress of the broken region, renitentsteaming on the tree, and additional scorching invoked to as trailing [9][10]. This ultimatelyterminate within the complete material failure of the cable and, typically, an electrical fulmination.Partial discharges lavish energy within the variety of heat, sound, and light. Localized heating from PD cause thermicdeterioration of the insulation.The purity of insulation in high voltage instruments will be accepted by observance of the PD activities that occur through the equipment's life.

\section{SIGNAL DENOISING}

In general PD doesn't cause instant breakdown. It express the existence of a defect inside the insulation which might have an effect on its performance in an exceedingly long run. In the chapter explains regarding the denoising techniques that are secondhand to denoise the Partial discharge signals in an efficient manner. The noise is especially generate by pours and exposes that WTstrategies displays best results compared to different filtering procedure by the signal to reconstruction error ratio (SRER) and reduction in noise level (RNL).

\section{A. Wavelet Transform}

In virtual signal processing and picture compression, wavelet is used and wavelet is a mathematical function. Firstly Wavelet compression is analysing a picture or image and secondly set of mathematical expressions is formed and then the receiver is used for decoded purpose. In recent years, Wavelet Transform (WT) has been adopted as an alternative algorithm for the analysis of non-stationary PD waveform. Comparing frequency/time-based filters, WT is more suitable for de-noising PD signals. In Wavelet, both time and frequency domains are used for analyse the signal and high and low-frequency components are used for analyse the sharp spikes in a signal and regains the originality of the signal.

\section{B.Types of Wavelet Transform}

$\begin{array}{ll}\text { - } & \text { Daubechies Wavelet } \\ \text { - } & \text { Coiflet Wavelet } \\ \text { - } & \text { Biorthogonal Wavelet } \\ \text { - } & \text { Symlet Wavelet } \\ & \text { Fejér-Korovkin Wavelet }\end{array}$

\section{EVALUATED PARAMETERS}

\section{A.Signal to Reconstruction Error Ratio (SRER)}

It is defined as the ratio of the power of the signal to the power of the noise. Equation (1) shows a SNR value,where $\mathbf{s}(\mathbf{i})$ is the PD signal, $\mathbf{n}(\mathbf{i})$ is the noise signal and $\mathbf{N}$ the number of sampIes.
$\operatorname{SRER}(\mathrm{dB})=10 \log _{10} \frac{\sum_{i=1}^{N} S^{2}(i)}{\sum_{i=1}^{N} n^{2}(i)}$

\section{B. Reduction in Noise Level (RNL)}

RNL is determined by,

$\mathrm{RNL}=10 \log _{n} \frac{1}{n} \sum_{i=1}^{n}(Z(i)-Y(i))^{2}$

Where, $\mathbf{Z}(\mathbf{i})$ is the noisy signal acquired, $\mathbf{Y}(\mathbf{i})$ is the denoised signal and $\mathbf{n}$ is the number of samples. Equation (2) shows a RNL value.

\section{RESULT DISCUSSION}

In this section, the results obtained within the limited period for completion of the project. Different type of defects are created in low tension cable. PD waveform is obtained from Partial Discharge meter. Normally PD signal contains noise, so this must be reduced because obtaining exact signal. The wavelet signal de-noising method is used for de-noising the PD signal with the help of MATLAB. The Signal to Reconstruction Error Ratio (SRER) and Reduction in Noise Level (RNL) are compared in different types of mother wavelets.

\section{A. Partial Discharge Waveform in Pure Cable}

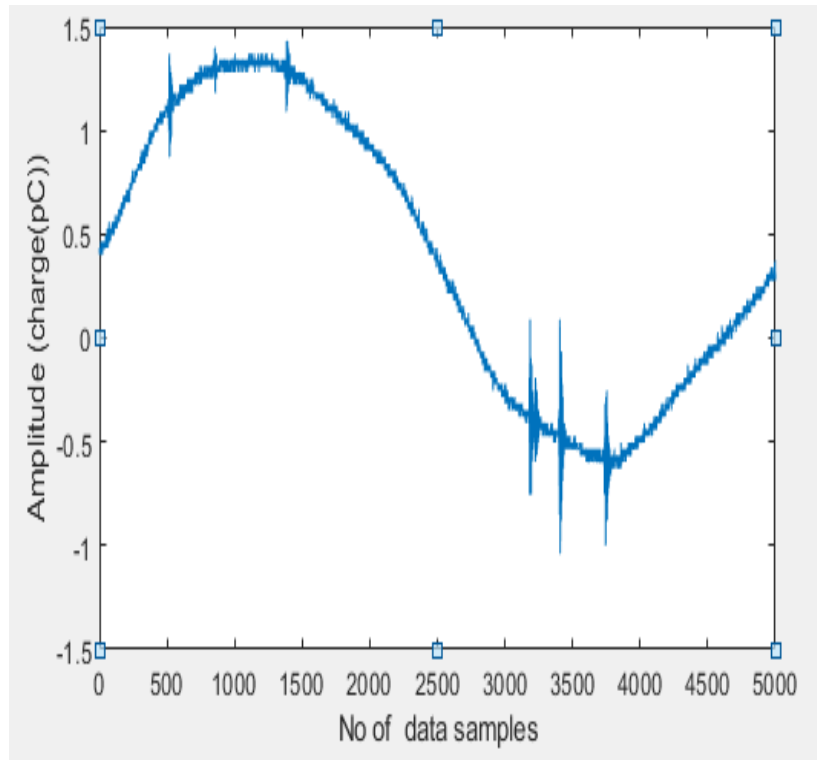

Fig.7. PD waveform for pure cable

Fig. 7 shows a PD waveform for pure cable. Fig. 8 shows 3D image of pure cable. This PD waveform contains PD magnitude and noise signal. This noise signal must be eliminated to obtain the exact PD waveform. It can be done by different mother wavelets. Table.I- VI shows a SRER and RNL values for different mother wavelets. 


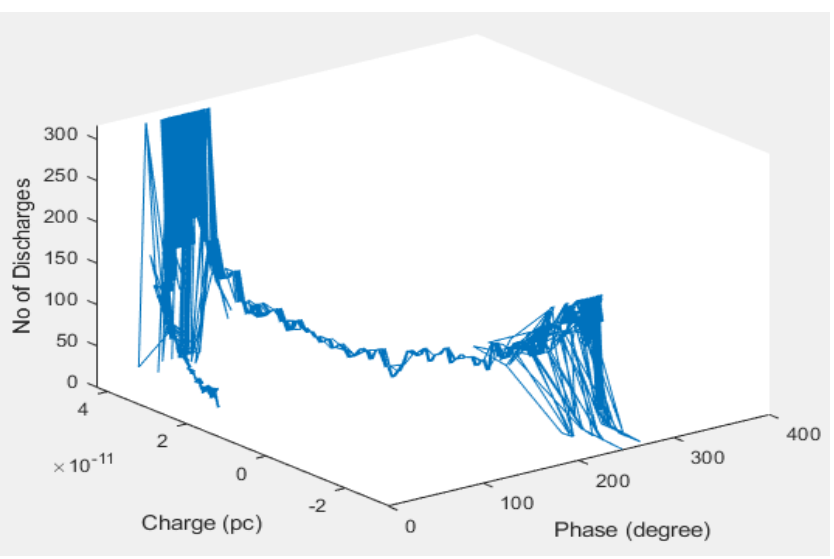

Fig.8. 3D plot of pure cable

Table-I: SRER and RNL in SYM wavelet for pure cable

\begin{tabular}{|c|c|c|}
\hline SYMLET & SRER & RNL \\
\hline 2 & 30.5154 & -64.5154 \\
\hline 3 & 30.5944 & -64.5831 \\
\hline 4 & 30.6982 & -65.0393 \\
\hline 5 & 30.6121 & -64.7995 \\
\hline 6 & 30.8418 & -65.0619 \\
\hline 7 & 30.8353 & -65.5532 \\
\hline 8 & 30.9579 & -65.6880 \\
\hline
\end{tabular}

Table- II: SRER and RNL in COIF wavelet for pure cable

\begin{tabular}{|c|c|c|}
\hline COIF & SRER & RNL \\
\hline 1 & 30.5474 & -64.5074 \\
\hline 2 & 30.7885 & -65.2702 \\
\hline 3 & 30.9288 & -65.7569 \\
\hline 4 & 30.9947 & -65.8069 \\
\hline 5 & 31.0573 & -65.9337 \\
\hline
\end{tabular}

Table- III: SRER and RNL in FK wavelet for pure cable

\begin{tabular}{|c|c|c|}
\hline FK & SRER & RNL \\
\hline 4 & 28.8955 & -62.1604 \\
\hline 6 & 30.5802 & -64.3063 \\
\hline 8 & 30.8378 & -65.0967 \\
\hline 14 & 31.0779 & -65.8317 \\
\hline 18 & 31.1380 & -65.9012 \\
\hline 22 & 31.1290 & -65.865 \\
\hline
\end{tabular}

Table- IV: SRER and RNL in BIOR wavelet for pure cable

\begin{tabular}{|c|c|c|}
\hline BIOR & SRER & RNL0 \\
\hline 1.1 & 28.2424 & -61.1567 \\
\hline 1.3 & 28.4479 & -64.7975 \\
\hline 1.5 & 28.6229 & -65.6319 \\
\hline 2.2 & 30.8686 & -65.1237 \\
\hline 2.4 & 30.9755 & -65.4383 \\
\hline 2.6 & 31.0571 & -66.2663 \\
\hline 2.8 & 31.1252 & -66.3126 \\
\hline 3.1 & 29.7921 & -66.7652 \\
\hline 3.3 & 30.8946 & -65.9157 \\
\hline 3.5 & 31.0747 & -66.4418 \\
\hline 3.7 & 31.1755 & -66.6615 \\
\hline 3.9 & 31.2537 & -67.1663 \\
\hline 4.4 & 30.7733 & -64.9053 \\
\hline 5.5 & 30.5481 & -64.6345 \\
\hline 6.8 & 30.9686 & -65.4784 \\
\hline
\end{tabular}

Retrieval Number: B3991129219/2019@BEIESP
Table- V: SRER and RNL in DB wavelet for pure cable

\begin{tabular}{|c|c|c|}
\hline DB & SRER & RNL \\
\hline 1 & 28.2424 & -61.5167 \\
\hline 2 & 30.3516 & -64.5154 \\
\hline 3 & 30.5944 & -64.5831 \\
\hline 4 & 30.5826 & -64.5672 \\
\hline 5 & 30.7446 & -64.9545 \\
\hline 6 & 30.8093 & -65.3544 \\
\hline 7 & 30.8209 & -65.1979 \\
\hline 8 & 30.8631 & -65.1739 \\
\hline 9 & 30.8943 & -65.3601 \\
\hline 10 & 30.9541 & -65.7902 \\
\hline
\end{tabular}

Table- VI: Comparison of all mother wavelets for pure cable

\begin{tabular}{|c|c|c|}
\hline Mother wavelet & SRER & RNL \\
\hline SYM 8 & 30.9579 & -65.6880 \\
\hline COIF 4 & 30.9947 & -65.8069 \\
\hline FK 18 & 31.1380 & -65.9012 \\
\hline BIOR 3.9 & 31.2537 & -67.1663 \\
\hline DB 10 & 30.9541 & -65.7902 \\
\hline
\end{tabular}

Biorthogonal 3.9 gives a higher Signal to Reconstruction Error Ratio (SRER) and Reduction in Noise Level (RNL) comparing all the mother wavelets levels. Denoising PD waveform shown in Fig 9.
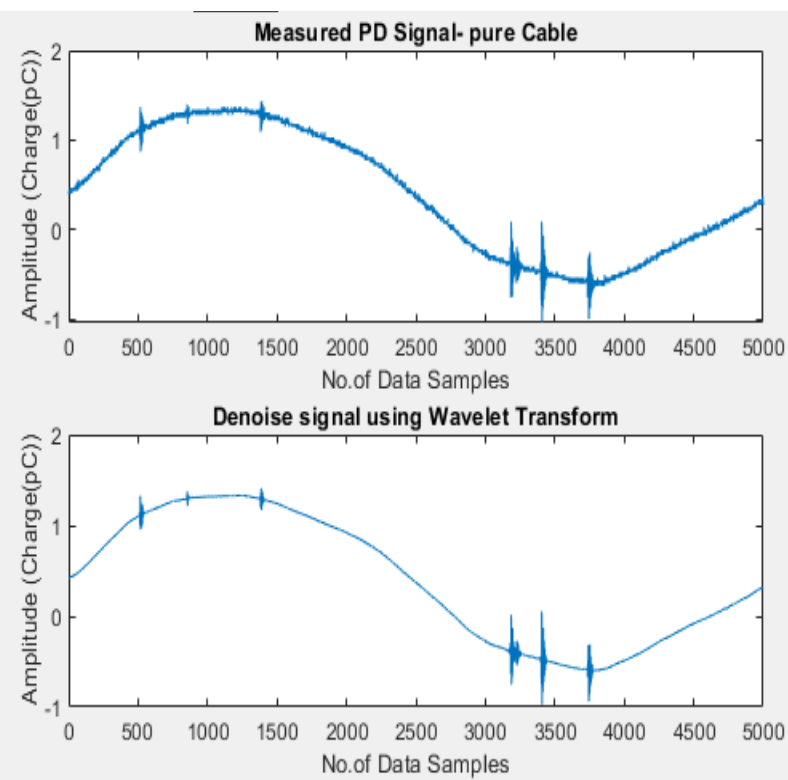

Fig.9. Denoised PD waveform for pure cable 
B. Partial Discharge Waveform in $2 \mathrm{~mm}$ Cylindrical Void Cable

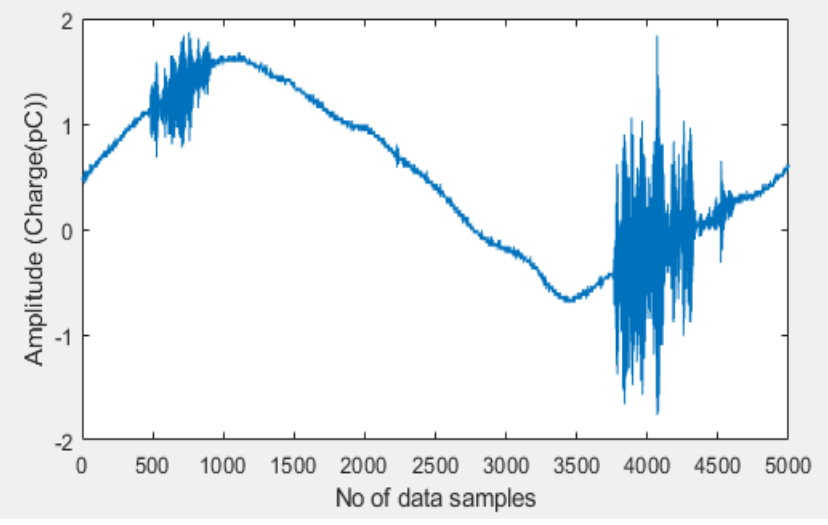

Fig.10. PD waveform for $2 \mathrm{~mm}$ cylindrical cable

Fig. 10 shows a PD waveform for $2 \mathrm{~mm}$ cylindrical cable. Fig. 11 shows a $3 \mathrm{D}$ image of $2 \mathrm{~mm}$ cylindrical cable. This PD waveform contains PD magnitude and noise signal. This noise signal must be eliminated to obtain the exact PD waveform. It can be done by different mother wavelets. Table. VII - XII shows a SRER and RNL values for different mother wavelets.

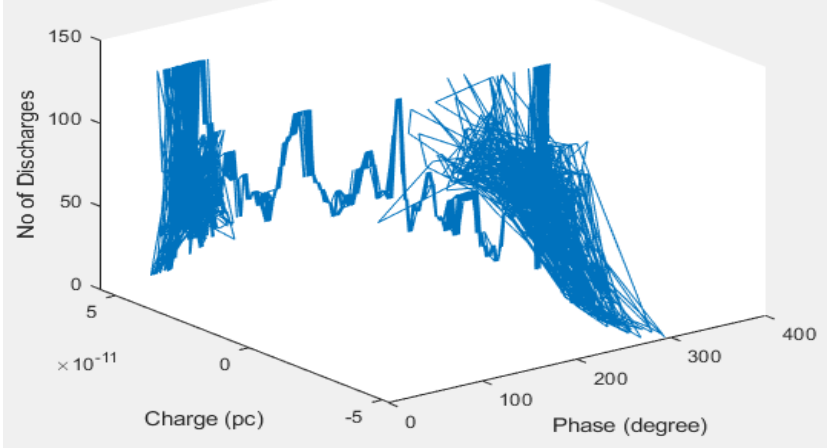

Fig.11. 3D image of $2 \mathrm{~mm}$ cylindrical cable

Table- VII: SRER and RNL in SYM wavelet for $2 \mathrm{~mm}$ cylindrical cable

\begin{tabular}{|c|c|c|}
\hline SYMLET & SRER & RNL \\
\hline 2 & 25.1162 & -43.6249 \\
\hline 3 & 25.8268 & -44.8245 \\
\hline 4 & 25.9971 & -45.1695 \\
\hline 5 & 25.5768 & -44.7508 \\
\hline 6 & 26.5681 & -46.1530 \\
\hline 7 & 26.6364 & -46.3606 \\
\hline 8 & 26.8183 & -46.6292 \\
\hline
\end{tabular}

Table- VIII: SRER and RNL in COIF wavelet for $2 \mathrm{~mm}$ cylindrical cable

\begin{tabular}{|c|c|c|}
\hline COIF & SRER & RNL \\
\hline 1 & 26.0327 & -44.7475 \\
\hline 2 & 26.5524 & -45.8373 \\
\hline 3 & 26.7766 & -46.4333 \\
\hline 4 & 26.8967 & $-46 . .7712$ \\
\hline 5 & 27.1552 & -47.1554 \\
\hline
\end{tabular}
waveform shown in Fig.12.

\begin{tabular}{|c|c|c|}
\hline FK & SRER & RNL \\
\hline 4 & 24.0197 & -42.3679 \\
\hline 6 & 26.2398 & -45.4070 \\
\hline 8 & 26.4576 & -45.9490 \\
\hline 14 & 27.5437 & -47.6539 \\
\hline 18 & 27.4337 & -47.4388 \\
\hline 22 & 27.6052 & -47.6383 \\
\hline
\end{tabular}

Table- X: SRER and RNL in BIOR wavelet for $2 \mathrm{~mm}$ cylindrical cable

\begin{tabular}{|c|c|c|}
\hline BIOR & SRER & RNL \\
\hline 1.1 & 23.5206 & -41.5877 \\
\hline 1.3 & 23.8639 & -42.9348 \\
\hline 1.5 & 24.1337 & -43.3952 \\
\hline 2.2 & 27.4788 & -46.6830 \\
\hline 2.4 & 27.8261 & -47.6237 \\
\hline 2.6 & 27.9752 & -48.2761 \\
\hline 2.8 & 28.1743 & -49.0619 \\
\hline 3.1 & 25.6263 & -49.0624 \\
\hline 3.3 & 26.8594 & -46.2554 \\
\hline 3.5 & 27.3555 & -47.3379 \\
\hline 3.7 & 27.5307 & -48.3457 \\
\hline 3.9 & 27.6372 & -48.8992 \\
\hline 4.4 & 26.7306 & -46.0028 \\
\hline 5.5 & 25.7715 & -44.7542 \\
\hline 6.8 & 27.1963 & -47.0455 \\
\hline
\end{tabular}

Table- XI: SRER and RNL in DB wavelet for $2 \mathrm{~mm}$ cylindrical cable

\begin{tabular}{|c|c|c|}
\hline DB & SRER & RNL \\
\hline 1 & 23.5206 & -41.5877 \\
\hline 2 & 25.1162 & -43.6249 \\
\hline 3 & 25.8268 & -44.8245 \\
\hline 4 & 25.5973 & -44.6529 \\
\hline 5 & 25.9294 & -45.2433 \\
\hline 6 & 26.3976 & -46.0303 \\
\hline 7 & 26.4096 & -45.9432 \\
\hline 8 & 26.5532 & -46.2111 \\
\hline 9 & 26.7201 & -46.6542 \\
\hline 10 & 27.1088 & -47.0654 \\
\hline
\end{tabular}

Table- XII: Comparison of all mother wavelets for $2 \mathrm{~mm}$ cylindrical cable

\begin{tabular}{|c|c|c|}
\hline $\begin{array}{c}\text { MOTHER } \\
\text { WAVELET }\end{array}$ & SRER & RNL \\
\hline SYM 8 & 26.8183 & -46.6292 \\
\hline COIF 5 & 27.1552 & -47.1554 \\
\hline FK 22 & 27.6052 & -47.6383 \\
\hline BIOR 2.8 & 28.1743 & -49.0619 \\
\hline DB 10 & 27.1088 & -47.0654 \\
\hline
\end{tabular}

Biorthogonal 2.8 gives a higher Signal to Reconstruction Error Ratio (SRER) and Reduction in Noise Level (RNL) comparing all the mother wavelets levels. Denoising PD

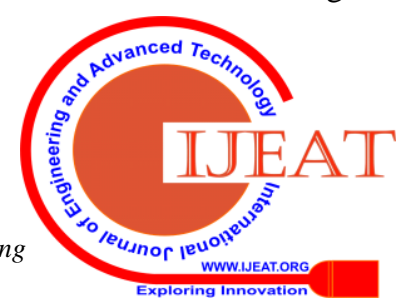




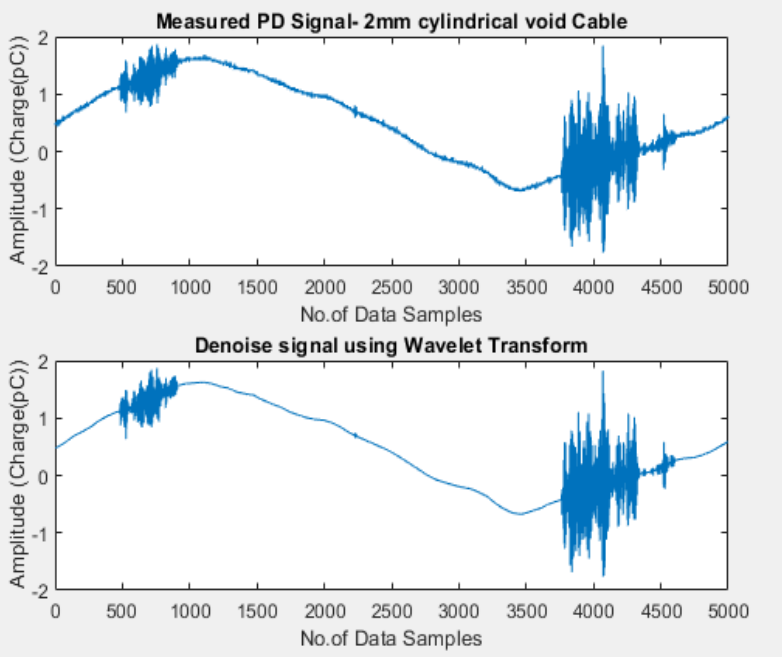

Fig.12. Denoised PD waveform for $2 \mathrm{~mm}$ cylindrical void cable

\section{Partial Discharge Waveform in $5 \mathrm{~mm}$ Cylindrical Void Cable}

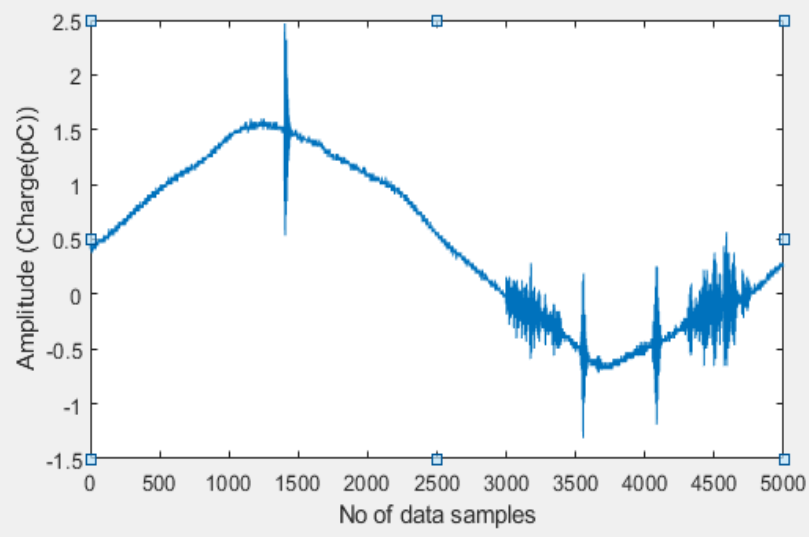

Fig.13. PD waveform for $\mathbf{5 m m}$ cylindrical cable

Fig. 13 shows a PD waveform for pure cable. Fig. 14 shows a 3D image of $5 \mathrm{~mm}$ cylindrical cable. This PD waveform contains PD magnitude and noise signal. This noise signal must be eliminated to obtain the exact PD waveform. It can be done by different mother wavelets. Table. XIII - XVIII shows a SRER and RNL values for different mother wavelets.

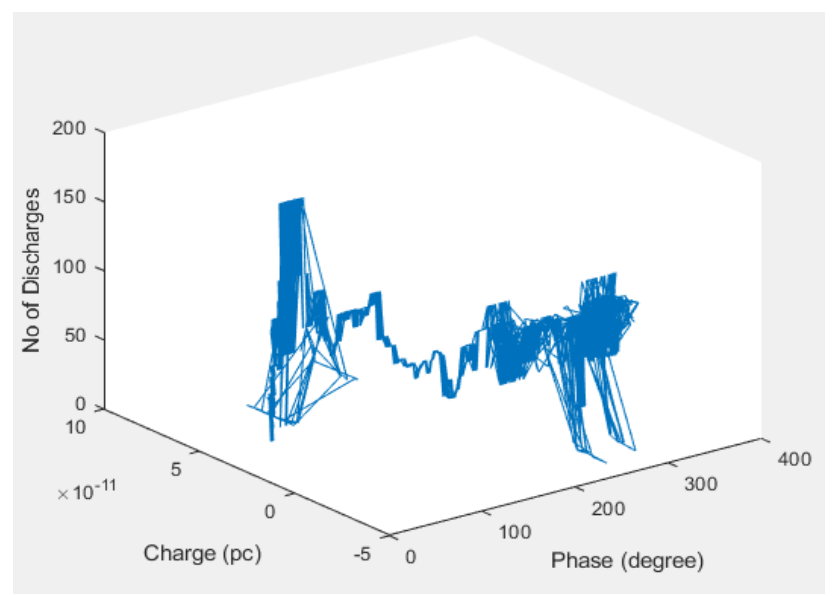

Fig.14. 3D image of $5 \mathrm{~mm}$ cylindrical cable

Table- XIII: SRER and RNL in SYM wavelet for $5 \mathrm{~mm}$ cylindrical cable

\begin{tabular}{|c|c|c|}
\hline SYMLET & SRER & RNL \\
\hline 2 & 27.1424 & -52.7675 \\
\hline 3 & 27.6807 & -53.7615 \\
\hline 4 & 27.8171 & -54.0651 \\
\hline 5 & 27.5537 & -53.8638 \\
\hline 6 & 28.4060 & -54.7979 \\
\hline 7 & 28.2737 & -54.6908 \\
\hline 8 & 28.6812 & -55.1839 \\
\hline
\end{tabular}

Table- XIV: SRER and RNL in COIF wavelet for $5 \mathrm{~mm}$ cylindrical cable

\begin{tabular}{|c|c|c|}
\hline COIF & SRER & RNL \\
\hline 1 & 27.4997 & -53.3687 \\
\hline 2 & 28.0916 & -54.3746 \\
\hline 3 & 28.4693 & -54.8485 \\
\hline 4 & 28.7301 & -55.1695 \\
\hline 5 & 28.9346 & -55.4211 \\
\hline
\end{tabular}

Table- XV: SRER and RNL in FK wavelet for $5 \mathrm{~mm}$ cylindrical cable

\begin{tabular}{|c|c|c|}
\hline FK & SRER & RNL \\
\hline 4 & 25.4136 & -51.0291 \\
\hline 6 & 27.8380 & -54.0548 \\
\hline 8 & 28.0647 & --54.4072 \\
\hline 14 & 29.1857 & -55.7715 \\
\hline 18 & 29.3049 & -55.9937 \\
\hline 22 & 29.1518 & -56.0307 \\
\hline
\end{tabular}

Table- XVI: SRER and RNL in BIOR wavelet for $5 \mathrm{~mm}$ cylindrical cable

\begin{tabular}{|c|c|c|}
\hline BIOR & SRER & RNL \\
\hline 1.1 & 29.3400 & -56.1901 \\
\hline 1.3 & 25.2965 & -52.0608 \\
\hline 1.5 & 25.4715 & -52.3467 \\
\hline 2.2 & 28.4657 & -54.7439 \\
\hline 2.4 & 28.8515 & -55.6651 \\
\hline 2.6 & 28.9915 & -56.1389 \\
\hline 2.8 & 29.1951 & -56.7561 \\
\hline 3.1 & 27.3290 & -54.7122 \\
\hline 3.3 & 28.5797 & -55.0712 \\
\hline 3.5 & 28.8279 & -55.7775 \\
\hline 3.7 & 29.0894 & -56.6805 \\
\hline 3.9 & 29.2191 & -56.9328 \\
\hline 4.4 & 28.3285 & -54.5797 \\
\hline 5.5 & 27.4553 & -53.4232 \\
\hline 6.8 & 28.9055 & -55.3686 \\
\hline
\end{tabular}


Table- XVII: SRER and RNL in DB wavelet for $5 \mathrm{~mm}$ cylindrical cable

\begin{tabular}{|c|c|c|}
\hline DB & SRER & RNL \\
\hline 1 & 24.8076 & -50.1707 \\
\hline 2 & 27.1424 & -52.9675 \\
\hline 3 & 27.6807 & -53.7615 \\
\hline 4 & 27.1056 & -53.1968 \\
\hline 5 & 27.6866 & -53.9358 \\
\hline 6 & 28.2244 & -54.6420 \\
\hline 7 & 28.3649 & -54.7991 \\
\hline 8 & 28.7259 & -55.2119 \\
\hline 9 & 28.6055 & -55.1314 \\
\hline 10 & 28.8486 & 55.4171 \\
\hline
\end{tabular}

Table- XVIII: Comparison of all mother wavelets for $5 \mathrm{~mm}$ cylindrical cable

\begin{tabular}{|c|c|c|}
\hline $\begin{array}{c}\text { MOTHER } \\
\text { WAVELET }\end{array}$ & SRER & RNL \\
\hline SYM 8 & 28.6812 & -55.1839 \\
\hline COIF 5 & 28.9346 & -55.4211 \\
\hline FK 18 & 29.3049 & -55.9937 \\
\hline BIOR 3.9 & 29.2191 & -56.9328 \\
\hline DB 10 & 28.8486 & 55.4171 \\
\hline
\end{tabular}

Biorthogonal 3.9 gives a higher Signal to Reconstruction Error Ratio (SRER) and Reduction in Noise Level (RNL) comparing all the mother wavelet levels. Denoising PD waveform shown in Fig. 15.

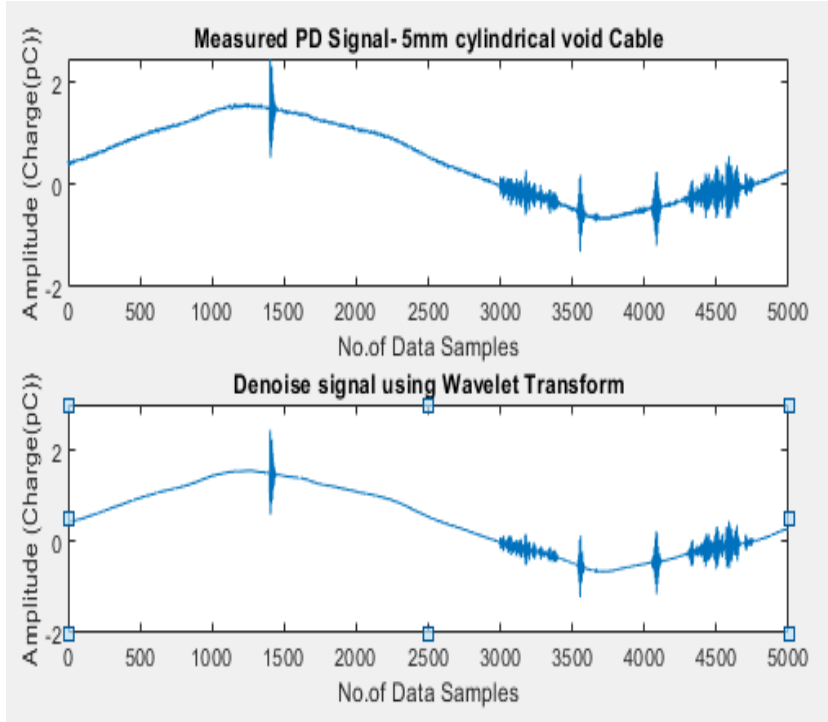

Fig.15. Denoised PD waveform for 5mm cylindrical void cable

The proposed method WT which overcomes the problem (i.e) noise present in the measured PD signal. Wavelet Transform approach is used for noise reduction goal, it recovers the novelty of the signal after denoising. To evaluate the effectiveness of the PD signal denoising Wavelets. The statistical parameters like SRER and RNL are computed, compared and tabularized in Tables VI, XII, XVIII for all cases. Biorthogonal Mother Wavelet produces the better result among other Mother wavelets.

\section{CONCLUSION}

In this work, cylindrical defects is imported into a $1.1 \mathrm{kV}$ XLPE cable. The PD characteristics of cylindrical cavities with various void diameter have been experimentally investigated. In this planned technique, Wavelet Transform (WT) is employed to denoise the PD signal in a very more practical manner. By evaluating the two totally different parameters it's clearly shows that the suggested denoised technique has a worthy SNR and RNL values. The noise existence within the signal ought to be low solely within the case that the SNR worth ought to be higher. The RNL shows high worth, that describes however expeditiously the noise is eliminated from the PD signal. Among the five different mother wavelets, Biorthogonal (Bior) shows a better result to denoise the PD measured signal.

\section{REFERENCES}

1. Xiao $\mathrm{Gu}$, Shuang $\mathrm{He}$, Yang $\mathrm{Xu}$, Youxiang Yan,Shuai Hoand Mingli Fu, "Partial Discharge Detection on $320 \mathrm{kV}$ VSC-HVDC XLPE Cable with Artificial Defects under DC Voltage", IEEE Transactions on Dielectrics and Electrical Insulation, Vol. 25, No. 3 pp. 939 - 946, 2018.

2. H.A.Illias, M.A.Tunio, A.H.A. Bakar, H.Mokhlis and G.Chen, "Partial Discharge Phenomena within an Artificial Void in Cable Insulation Geometry: Experimental Validation and Simulation", IEEE Transactions on Dielectrics and Electrical Insulation, Vol. 23, No.1, pp. 451 - 459, 2016

3. Hazlee Illias, George Chen and Paul L. Lewin, "Partial Discharge Behavior within a Spherical Cavity in a Solid Dielectric Material as a Function of Frequency and Amplitude of the Applied Voltage", IEEE Transactions on Dielectrics and Electrical Insulation, Vol. 18, No.2, pp. 432 - 443, 2011.

4. Weiwei Li, Jianying Li, Guilai Yin, Shengtao, Li Jiankang Zhao and Benhong Ouyang, "Frequency Dependence of Breakdown Performance of XLPE with Different Artificial Defect", IEEE Transactions on Dielectrics and Electrical Insulation, Vol.19, No. 4, pp. 1351 - 1359, 2012.

5. Yunfeng Xia,Xinming Song, Jianzong He, Zhidong Jia and Xilin Wang, "Simulation and partial discharge detection for typical defects of $10 \mathrm{kV}$ cable the joint", IET The Journal of Engineering, Vol. Iss.16,pp. 2856 - 2859, 2019.

6. Zhipeng Lei, Jiancheng Song, Muqin Tian, Xiaohui Cui, Chuanyang $\mathrm{Li}$ and Minmin Wen, "Partial Discharges of Cavities in Ethylene Propylene Rubber Insulation", IEEE Transactions on Dielectrics and Electrical Insulation, Vol. 21, No. 4, pp. 1647 - 1659, 2014.

7. A.B.J.M. Driessen, J.van Duivenbode and P.A.A.F.Wouters, "Partia Discharge Detection for Characterizing Cable Insulation under Low and Medium Vacuum Conditions", IEEE Transactions on Dielectrics and Electrical Insulation, Vol. 25, No. 1, pp. 306 - 315, 2018.

8. M. Runde, O. Kvien, H. Förster and N. Magnusson, "Cavities in Mass-Impregnated HVDC Subsea Cables Studied by AC Partial Discharge Measurements", IEEE Transactions on Dielectrics and Electrical Insulation, Vol. 26, No. 3, pp. 913 - 921, 2019.

9. H.Okubo, H.Kojima, F.Endo, K.Sahara, R.Yamaguchi, and N.Hayakawa, "Partial Discharge Activity in Electrical Insulation for High Temperature Superconducting (HTS) Cables", IEEE Transactions on Dielectrics and Electrical Insulation, Vol. 15, No. 3, pp. 647 - 654, 2008

10. S.Mousavi Gargari, P.A.A.F.Wouters, P.C.J.M.van der Wielen and E .F Steennis, "Partial Discharge Parameters to Evaluate the Insulation Condition of On-line Located Defects in Medium Voltage Cable Networks",IEEE Transactions on Dielectrics and Electrical Insulation, Vol. 18, No. 3, pp. 868 - 877, 2011. 


\section{AUTHORS PROFILE}

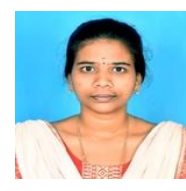

S. Madhupriya received BE Degree in electrical and electronics engineering in 2018 at the National Engineering College, Kovilpatti. She is studying final year high voltage Engineering in National Engineering College, Kovilpatti. Her area of interest is partial discharge.

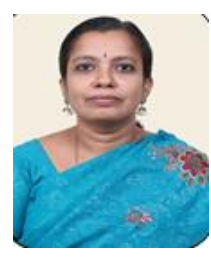

Dr. R. V. Maheswari received BE Degree in electrical and electronics engineering in 2000 at the Government College of Engineering, Tirunelveli, ME (high voltage engineering) in 2008 at the National Engineering College and $\mathrm{PhD}$ (electrical engineering) from the Anna University, India in 2015. Presently, she is working as Professor in EEE Department of the National Engineering College, Kovilpatti. She has more than 13 years of teaching experience in engineering institutions. She has published twenty papers in international conferences and eight international journals. She is an active member of IEEE, IE (I) and ISTE. Her research interests are characteristics of partial discharge, numerical analysis, pattern recognition and modeling of partial discharge.

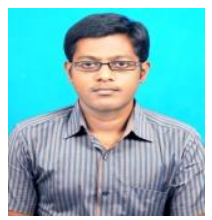

Mr. B. Vigneshwaran received his B.E. and M.E. Degree from P.S.R. Engineering College, Sivakasi and National Engineering College in 2011 and 2013 respectively. His area of specialization is High Voltage Engineering. At present he is an Assistant Professor (Senior Grade) in EEE Department of National Engineering College. Totally he has published 9 papers in International Conferences and 8 papers in International Journal. $\mathrm{He}$ is an ISTE member His research interests are Characteristics of Machine learning, Partial discharge pattern analysis and FEM 